\section{The Use of Sawdust Mixed with Ground Branches Pruned from Wax Apple or Indian Jujube as Substrate for Cultivation of King Oyster Mushroom (Pleurotus eryngii)}

\author{
San-Gwang Hwang, Yi-Ying Li, and Huey-Ling Lin ${ }^{1}$ \\ Department of Horticulture, National Chung Hsing University, \\ 250 Kuo Kuang Road, 402 Taichung, Taiwan, Republic of China
}

Additional index words. mycelium growth, mushroom fruiting conditions, sawdust, mineral elements

\begin{abstract}
The king oyster mushroom [Pleurotus eryngii (DC.:Fr.) Quél.] is gaining popularity across the world due to its excellent taste, high nutritional quality, medicinal value, and long shelf life. Conventional substrates for king oyster mushroom cultivation consist of sawdust derived from various tree species. Sawdust demand is increasing worldwide, creating a need for alternative materials that can at least partially replace sawdust as substrate for king oyster mushroom. In Taiwan, as in other countries that grow fruit trees, pruned fruit tree branches are an expensive agricultural waste, particularly if they are not recycled or reused. In the present study, we evaluated substrates containing sawdust and different proportions of material ground from pruned wax apple or Indian jujube branches for cultivation of king oyster mushroom. Our results suggested that among all five substrate mixes tested, the best substitute for conventional sawdust $(\mathbf{1 0 0} \%$ sawdust) was a substrate that contained $\mathbf{7 5 \%}$ sawdust mixed with $25 \%$ materials ground from trimmed wax apple branches (Wax apple $25 \%$ ). Furthermore, determination of mineral element content, $\mathrm{pH}$, and electrical conductivity (EC) levels of the substrates both before spawn inoculation and after harvesting revealed no significant changes in mineral content, a slight reduction in $\mathrm{pH}$ value, and a minor increase in EC levels after cultivation. Taken together, results from this study suggest that agricultural wastes from pruned fruit tree branches can partially replace sawdust as the cultivation substrate for king oyster mushroom.
\end{abstract}

The king oyster mushroom (Pleurotus eryngii) is classified as a white rot fungus capable of digesting lignocellulose (Sharma and Arora, 2015). Currently, lignocellulosic materials such as sawdust obtained from various tree species are widely used for commercial production of this mushroom (Peng, 1997; Yamanaka, 2011). Due to the crisis of global warming, the role as carbon sink of forest trees has received much attention, with the aim of reducing use of raw tree materials. Thus, many research efforts have focused on finding lignocellulosic wastes suitable for mushroom production to replace sawdust, which is often associated with deforestation (Baysal, 2003; Kurt and Buyukalaca, 2010; Obodai et al., 2003; Petre and Teodorescu, 2012; Rani et al., 2008; Yildiz et al., 2002; Zervakis, 2005).

According to Poppe (2000), at least 200 agroforestry wastes can be used for oyster mushroom production. However, numerous studies have indicated that individual

Received for publication 20 Jan. 2015. Accepted for publication 16 Apr. 2015.

${ }^{1}$ Corresponding author. E-mail: hllin@dragon.nchu. edu.tw. markets that rely on imports. On the other hand, horticultural wastes, such as the trimmed branches of fruit trees, are a good source of lignocellulose. However, it is unknown whether pruned fruit tree branches can serve as an alternative substrate for king oyster mushroom growth. In Taiwan, around 5113 ha of land are devoted to wax apple [Syzygium samarangense (Blume) Merrill \& Perry] cultivation, with $70 \%$ to $80 \%$ of wax apple tree branches pruned annually to achieve off-season production. Additionally, around 2048 ha of land in Taiwan are used for Indian jujube (Ziziphus mauritiana Lam.) production (Council of Agriculture-Taiwan, 2013), with annual tree pruning a common practice among growers to obtain higher yields. These pruned fruit tree branches are a horticultural waste and their removal from the orchard are an expense. In the present study, we investigated the potential of ground branches pruned from wax apple or Indian jujube trees to partially substitute sawdust in king oyster mushroom cultivation.

\section{Materials and Methods}

Preparation of mushroom growing materials and spawn inoculation. The spawn of a commercial king oyster mushroom strain (Ruifeng-6) and sawdust were provided by a local farm located in Taichung, Taiwan. Pruned wax apple and Indian jujube tree branches were collected from the Horticulture Research Station at the College of Agriculture and Natural Resources, National Chung Hsing University, Taichung, Taiwan. Pruned fruit tree branches including leaves were first completely dried in a $70{ }^{\circ} \mathrm{C}$ oven for 2-3 $\mathrm{d}$ and then ground in a small batch pulverizing machine to 25-mesh size (Model RT-01A; Rong Tsong Precision Technology Co., Taiwan). In this study, five mixes were prepared: sawdust as the control (Sawdust $100 \%$ ), 25\% replacement of sawdust with materials ground from pruned wax apple (Wax apple 25\%) or Indian jujube (Indian jujube $25 \%$ ) tree branches, and 50\% replacement of sawdust with materials ground from pruned wax apple (Wax apple $50 \%$ ) or Indian jujube (Indian jujube $50 \%$ ) tree branches. The water content of the five sawdust-based mixes was adjusted to $60 \%$ by weight with tap water. The final substrates contained standard ingredients in a ratio (w/w) of $89 \%$ wet sawdust mix, $5 \%$ dried rice bran, $5 \%$ dried wheat bran, and $1 \%$ calcium carbonate and were packed into a polyethylene $(\mathrm{PE})$ bag $(36 \mathrm{~cm} \times 9 \mathrm{~cm})$. The overall water content of the mixed substrate inside the PE bag was then adjusted to $62 \%$ using tap water. A cotton plug was inserted into the bag and a ring wrapped around the neck to seal the PE bag. The finished PE bags containing $980 \mathrm{~g}$ of cultivation substrate were autoclaved at $100{ }^{\circ} \mathrm{C}$ for $8 \mathrm{~h}$, cooled to $30{ }^{\circ} \mathrm{C}$ at room temperature, and then inoculated with $15-18 \mathrm{~g} / \mathrm{bag}$ of Ruifeng- 6 king oyster spawn.

Evaluation of mycelium growth and mushroom fruiting conditions. After spawn inoculation, the PE bags were kept in the dark 
at $25{ }^{\circ} \mathrm{C}$. Ten culture bags were prepared for each of the five substrates. For each replicate, mycelium length, mycelium extension rate, mycelium density, mycelium color, and mycelium growth period (MGP) were monitored. The length of mycelium was recorded every $3 \mathrm{~d}$. The daily growth rate was then calculated as centimeters per day. A digital index was used to rate mycelium density, with 5 indicating the highest density and 1 the lowest. A color indexing system based on the mycelium color observed in $100 \%$ sawdust substrate was developed to describe mycelium color, with 5 representing pure white color and a yellowish-white color designated by 1 . The mycelium growth period was defined as the days after inoculation for the substrate to be fully colonized with mycelium.

After mycelium fully colonized the substrate, the PE bags were moved into a cropping room with a temperature of $15{ }^{\circ} \mathrm{C}$, a relative humidity $(\mathrm{RH})$ of more than $95 \%$, and a $\mathrm{CO}_{2}$ concentration below $3000 \mathrm{ppm}$ to promote fruiting body development. For all five substrates tested, the yield (total fresh weight of fruiting body/bag), the average length of fruiting body, the number of marketable fruiting bodies (with normal stipe, pileus, and a fresh weight of more than $15 \mathrm{~g}$ ), and the biological efficiency (fresh weight of mushroom/dry weight of substrate*100) were measured. Furthermore, average days after inoculation for the mushroom primordia to be first visible (denoted DPV) and average days from inoculation to harvest (denoted DIH) were also recorded. All measurements were repeated 10 times.

Measurement of substrate mineral elements. Substrate samples were first blanched in a $100{ }^{\circ} \mathrm{C}$ oven for $1 \mathrm{~h}$ and then placed in a $70{ }^{\circ} \mathrm{C}$ oven until completely dry. The dried substrate samples were ground into powder. Powder $(0.5 \mathrm{~g})$ was weighed into a crucible and heated in a muffle furnace at $200{ }^{\circ} \mathrm{C}$ for $2 \mathrm{~h}$, followed by $400^{\circ} \mathrm{C}$ for another $2 \mathrm{~h}$, and finally heated to ash at $550{ }^{\circ} \mathrm{C}$ for $2 \mathrm{~h}$. After cooling, $5 \mathrm{~mL}$ of $2 \mathrm{~N} \mathrm{HCl}$ (Merck, Germany) was added to completely dissolve the ash. The ash solution was filtered through a filter paper (Whatman \#42, USA) and the filtrate was diluted to $25 \mathrm{~mL}$ with deionized water in a PE plastic bottle. The content of iron $(\mathrm{Fe})$, manganese $(\mathrm{Mn})$, zinc $(\mathrm{Zn})$, and copper $(\mathrm{Cu})$ were quantitatively measured using an Atomic Absorption Spectrophotometer (Model Z-2300, Hitachi, Japan). After proper dilution of the filtrate, potassium $(\mathrm{K})$ and magnesium $(\mathrm{Mg})$ were likewise quantitatively determined. The same device was used to quantify calcium $(\mathrm{Ca})$ with the substrate sample prepared by taking $0.1 \mathrm{~g}$ of filtered ash solution and mixing with $3.9 \mathrm{~mL}$ of deionized water and $1 \mathrm{~mL}$ of lanthanum oxide.

A vanadate/molybdate method was adopted to determine phosphorus (P) content. Briefly, $1 \mathrm{~mL}$ of filtered ash solution was added to $3 \mathrm{~mL}$ of deionized water and $1 \mathrm{~mL}$ of vanadate/molybdate reagent, thoroughly mixed, and incubated for $10 \mathrm{~min}$.
The sample was subjected to spectrophotometric determination using the Hitachi U-2000 Spectrophotometer.

The micro-Kjeldahl method was used to analyze nitrogen $(\mathrm{N})$. Briefly, $1 \mathrm{~kg}$ of substrate sample was ground and dried in a $70{ }^{\circ} \mathrm{C}$ oven for one night. Then $0.2 \mathrm{~g}$ of dried sample was wrapped with filter paper (Whatman \#1) and placed into a digestion tube together with $1 \mathrm{~g}$ of catalyst (Merck 8030) and $4.5 \mathrm{~mL}$ of concentrated sulfuric acid. The mixture was placed in the digestion vessel and heated at $410{ }^{\circ} \mathrm{C}$ for $2.5-3 \mathrm{~h}$ until the sample became clear or light green in color. The digested sample was then poured into the Kjeldahl flask with addition of $20 \mathrm{~mL} 12 \mathrm{~N} \mathrm{NaOH}$. After reaction, $50 \mathrm{~mL}$ of the converted ammonia was collected in a plastic beaker containing $20 \mathrm{~mL}$ of $2 \%$ boric acid mixed with $19 \mu \mathrm{M}$ bromocresol green and $25 \mu \mathrm{M}$ methyl red indicator. The reaction was then titrated with $1 / 14 \mathrm{~N}$ sulfuric acid to determine the percentage of ammonia in the substrate sample.

Determination of substrate $p H$ and $E C$ values before inoculation and after harvesting. For each substrate evaluated, two PE bags were sampled $(100 \mathrm{~g})$ before inoculation and after harvesting to determine the $\mathrm{pH}$ and $\mathrm{EC}$ of the substrate. The two samples were thoroughly mixed in a plastic container, from which $100 \mathrm{~g}$ of well-mixed substrate was sampled, air-dried for $2-3 \mathrm{~d}$, and then stored in a sulfuric acid paper bag before measurement of $\mathrm{pH}$ and $\mathrm{EC}$. To determine the $\mathrm{pH}$ and $\mathrm{EC}$ values, $5 \mathrm{~g}$ of dried substrate sample was homogenized with $40 \mathrm{~mL}$ of purified water, incubated for $2 \mathrm{~h}$, and then filtered through gauze. The $\mathrm{pH}$ and $\mathrm{EC}$ of the liquid was determined with a $\mathrm{pH}$ meter (SP701; Suntex, Taiwan) and an EC meter (SC170; Suntex), respectively. In this analysis, three repeats were performed for each substrate tested.

Statistical analysis. Calculation of sample means, analysis of variance (ANOVA), and least significant difference (LSD) were performed using SAS ver. 9.0 (SAS Institute, Cary, NC).

\section{Results and Discussion}

Substrate effects on mycelium growth and mushroom fruiting. Substrate mixes containing various ratios of sawdust and wax apple or Indian jujube grindings were prepared and used to cultivate king oyster mushrooms. The four mixes showed no significant differences $(P<0.05)$ in mycelium length or mycelium extension rate at 14 or $42 \mathrm{~d}$ after spawn inoculation relative to control (Sawdust $100 \%$ ) (Tables 1 and 2). However, at $28 \mathrm{~d}$ after spawn inoculation, the mycelium length and mycelium extension rate values were significantly smaller in the substrate mixes with $25 \%$ or $50 \%$ ground Indian Jujube than in control $(P<0.05$; Tables 1 and 2$)$. The reason for this is not clear and requires further analysis.

The densest mycelium was observed in the Wax apple 25\% and Wax apple 50\% substrates (Table 3). The mycelium color appeared white in all substrates tested (Table 3). The shortest MGP was noted for Sawdust $100 \%$ and Wax apple $25 \%$ substrates, with values of 40.7 and $40.0 \mathrm{~d}$, respectively. In contrast, the other substrates were fully colonized with mycelium after more than $50 \mathrm{~d}$ (Table 3). Similarly, the earliest primordia were observed in Sawdust $100 \%$ and Wax apple 25\% substrates, with average DPV values of 56.5 and $55.4 \mathrm{~d}$, respectively (Table 3 ). These substrates also resulted in an earlier harvest (DIH, Table 3). The earliest harvest, at $68.0 \mathrm{~d}$ after inoculation, was obtained when king oyster mushroom was cultivated in Wax apple 25\% substrate (Table 3). These results suggested that up to $25 \%$ of the sawdust can be replaced with wax apple grindings.

The yield of mushroom in the Indian jujube $25 \%$ substrate was significantly lower $(P<0.05)$ than in the control (Sawdust $100 \%$ ) (Table 4). The highest yield was

Table 1. The effect of different substrate base mixes on mycelium length (centimeters).

\begin{tabular}{lcccr}
\hline & \multicolumn{4}{c}{ Days after inoculation } \\
\cline { 2 - 5 } Substrate Bases & 0 & 14 & 28 & 42 \\
\hline Sawdust $100 \%$ & $0.00 \mathrm{a}^{\mathrm{z}}$ & $1.31 \mathrm{a}$ & $6.58 \mathrm{a}$ & $15.23 \mathrm{a}$ \\
Wax apple 25\% & $0.00 \mathrm{a}$ & $1.17 \mathrm{a}$ & $5.00 \mathrm{ab}$ & $12.97 \mathrm{a}$ \\
Wax apple 50\% & $0.00 \mathrm{a}$ & $1.30 \mathrm{a}$ & $5.13 \mathrm{ab}$ & $12.95 \mathrm{a}$ \\
Indian jujube 25\% & $0.00 \mathrm{a}$ & $1.23 \mathrm{a}$ & $4.55 \mathrm{~b}$ & $12.88 \mathrm{a}$ \\
Indian jujube 50\% & $0.00 \mathrm{a}$ & $1.85 \mathrm{a}$ & $3.20 \mathrm{~b}$ & $11.90 \mathrm{a}$ \\
\hline
\end{tabular}

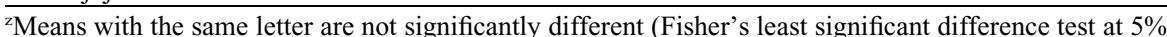
level).

Table 2. The effect of different substrate base mixes on mycelium extension rate (centimeter per day).

\begin{tabular}{lcccr}
\hline & \multicolumn{4}{c}{ Days after inoculation } \\
\cline { 2 - 4 } Substrate Bases & 0 & 14 & 28 & 42 \\
\hline Sawdust $100 \%$ & $0.00 \mathrm{a}^{\mathrm{z}}$ & $0.09 \mathrm{a}$ & $0.39 \mathrm{a}$ & $0.62 \mathrm{a}$ \\
Wax apple $25 \%$ & $0.00 \mathrm{a}$ & $0.08 \mathrm{a}$ & $0.29 \mathrm{ab}$ & $0.57 \mathrm{a}$ \\
Wax apple $50 \%$ & $0.00 \mathrm{a}$ & $0.09 \mathrm{a}$ & $0.28 \mathrm{ab}$ & $0.56 \mathrm{a}$ \\
Indian jujube $25 \%$ & $0.00 \mathrm{a}$ & $0.09 \mathrm{a}$ & $0.25 \mathrm{~b}$ & $0.55 \mathrm{a}$ \\
Indian jujube 50\% & $0.00 \mathrm{a}$ & $0.13 \mathrm{a}$ & $0.23 \mathrm{~b}$ & $0.62 \mathrm{a}$ \\
\hline z & &
\end{tabular}

${ }^{\mathrm{z}}$ Means with the same letter are not significantly different (Fisher's least significant difference test at 5\% level). 
observed in Wax apple 25\% substrate, with a value of $241.84 \mathrm{~g} / \mathrm{bag}$ (Table 4). No significant difference $(P<0.05)$ was recorded for the average length of fruiting body among the different substrates tested, with values ranging from 9.78 to $11.00 \mathrm{~cm}$ (Table 4). The number of marketable fruiting bodies was significantly $(P<0.05)$ smaller in Indian jujube $50 \%$ substrate (1.00) relative to control (3.18). No significant differences $(P<0.05)$ were detected among the other substrates, with values ranging from 1.88 to 3.18 (Table 4). Similar to the mycelium length and mycelium extension rate recorded at $28 \mathrm{~d}$ after spawn inoculation, biological efficiency was higher in Sawdust $100 \%$, Wax apple $25 \%$, and Wax apple $50 \%$ substrates, with efficiency values of more than $60 \%$ and no significant difference $(P<0.05)$ among them (Table 4$)$.

These results suggest that a substrate containing 25\% wax apple grindings may serve as a suitable alternative substrate for king oyster mushroom cultivation.
Low temperature effects on fruiting body yield and biological efficiency. Juang et al. (2012) reported that treatment of fully colonized PE bags with lower temperatures, such as $12{ }^{\circ} \mathrm{C}$ for $3-5 \mathrm{~d}$ or $15{ }^{\circ} \mathrm{C}$ for $5 \mathrm{~d}$, before shifting them to $17{ }^{\circ} \mathrm{C}$ (to induce primordia and fruiting body development) yielded 224 $229 \mathrm{~g} / \mathrm{bag}$ and a biological efficiency between $54.7 \%$ to $56.4 \%$, both significantly $(P<0.05)$ higher than bags cultivated at a constant temperature of $17{ }^{\circ} \mathrm{C}$. In the present study, a lower temperature of $15^{\circ} \mathrm{C}$ was constantly applied during the period of primordia induction and fruiting body development, which may in turn have resulted in the higher fruiting body yield and biological efficiency relative to those reported by Juang et al. (2012). Further detailed studies on temperature effects on fruiting body yield and biological efficiency should be conducted and include different periods of low temperature treatment.

Nutrient status of different substrates before inoculation and after harvesting. The mineral content of the substrate mixes and any

Table 3. Characteristics of mycelium growth in different substrates.

\begin{tabular}{lccccr}
\hline & Density index & Color index $^{\mathrm{y}}$ & MGP $^{\mathrm{x}}$ & DPV $^{\mathrm{w}}$ & DIH $^{\mathrm{v}}$ \\
\hline Sawdust $100 \%$ & $4 \mathrm{c}^{\mathrm{u}}$ & $5 \mathrm{a}$ & $40.7 \mathrm{~b}$ & $56.5 \mathrm{c}$ & $75.8 \mathrm{c}$ \\
Wax apple $25 \%$ & $5 \mathrm{a}$ & $5 \mathrm{a}$ & $40.0 \mathrm{~b}$ & $55.4 \mathrm{c}$ & $68.0 \mathrm{~d}$ \\
Wax apple $50 \%$ & $5 \mathrm{a}$ & $5 \mathrm{a}$ & $51.8 \mathrm{a}$ & $65.6 \mathrm{~b}$ & $82.3 \mathrm{~b}$ \\
Indian jujube $25 \%$ & $4 \mathrm{c}$ & $5 \mathrm{a}$ & $53.3 \mathrm{a}$ & $66.1 \mathrm{~b}$ & $84.8 \mathrm{~b}$ \\
Indian jujube $50 \%$ & $4.3 \mathrm{~b}$ & $5 \mathrm{a}$ & $57.1 \mathrm{a}$ & $75.5 \mathrm{a}$ & $93.6 \mathrm{a}$ \\
\hline
\end{tabular}

${ }^{2}$ The number 5 indicates the highest density and 1 indicates the lowest density.

${ }^{\mathrm{y}}$ The number 5 represents pure white color and 1 indicates a yellowish white color.

${ }^{\mathrm{x}}$ MGP: average days after inoculation for the substrate to be fully colonized with mycelium.

${ }^{w}$ DPV: average days after inoculation for the mushroom primordia to be first visible.

vDIH: average days from inoculation to harvest.

'Means with the same letter are not significantly different (Fisher's least significant difference test at 5\% level).

Table 4. Characteristics of fruiting body development in different substrates.

\begin{tabular}{lcccc}
\hline & Yield $(\mathrm{g} / \mathrm{bag})$ & Length $(\mathrm{cm})$ & $\begin{array}{c}\text { Number of marketable } \\
\text { fruiting bodies }\end{array}$ & $\begin{array}{c}\text { Biological } \\
\text { efficiency (\%) }\end{array}$ \\
\hline Sawdust $100 \%$ & $240.11 \mathrm{a}^{\mathrm{y}}$ & $10.52 \mathrm{a}$ & $3.18 \mathrm{a}$ & $64.42 \mathrm{a}$ \\
Wax apple $25 \%$ & $241.84 \mathrm{a}$ & $10.13 \mathrm{a}$ & $3.00 \mathrm{ab}$ & $64.88 \mathrm{a}$ \\
Wax apple $50 \%$ & $231.09 \mathrm{a}$ & $10.83 \mathrm{a}$ & $2.67 \mathrm{ab}$ & $61.97 \mathrm{a}$ \\
Indian jujube $25 \%$ & $165.20 \mathrm{~b}$ & $9.78 \mathrm{a}$ & $1.88 \mathrm{ab}$ & $44.30 \mathrm{~b}$ \\
Indian jujube $50 \%$ & $193.61 \mathrm{ab}$ & $11.00 \mathrm{a}$ & $1.00 \mathrm{~b}$ & $51.90 \mathrm{ab}$ \\
\hline
\end{tabular}

${ }^{\mathrm{z}}$ Fruiting body with normal stipe, pileus and a fresh weight of more than $15 \mathrm{~g}$.

${ }^{\mathrm{y}}$ Means with the same letter are not significantly different (Fisher's least significant difference test at 5\% level).

Table 5. Nutrient content in different substrates before inoculation.

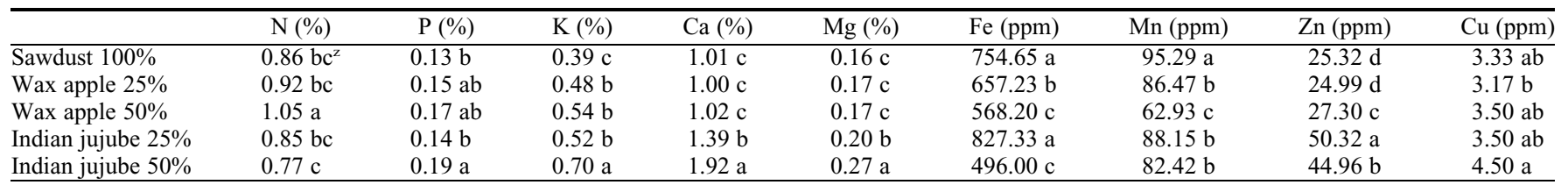

${ }^{\mathrm{z}}$ Means with the same letter are not significantly different (Fisher's least significant difference test at $5 \%$ level).

Table 6. Nutrient content in different substrates after harvesting.

\begin{tabular}{|c|c|c|c|c|c|c|c|c|c|}
\hline & $\mathrm{N}(\%)$ & $\mathrm{P}(\%)$ & K (\%) & $\mathrm{Ca}(\%)$ & $\mathrm{Mg}(\%)$ & $\mathrm{Fe}(\mathrm{ppm})$ & $\mathrm{Mn}(\mathrm{ppm})$ & $\mathrm{Zn}(\mathrm{ppm})$ & $\mathrm{Cu}(\mathrm{ppm})$ \\
\hline Sawdust $100 \%$ & $0.86 b^{z}$ & $0.28 \mathrm{~b}$ & $0.39 \mathrm{~d}$ & $1.43 \mathrm{~d}$ & $0.22 \mathrm{~d}$ & $340.86 \mathrm{~b}$ & $73.97 \mathrm{a}$ & $23.33 \mathrm{~d}$ & $3.17 \mathrm{~d}$ \\
\hline Wax apple $25 \%$ & $0.97 \mathrm{~b}$ & $0.33 \mathrm{a}$ & $0.48 \mathrm{c}$ & $1.63 b c$ & $0.25 \mathrm{c}$ & $374.74 \mathrm{~b}$ & $73.45 \mathrm{ab}$ & $25.82 \mathrm{c}$ & $3.83 \mathrm{~cd}$ \\
\hline Wax apple $50 \%$ & $1.23 \mathrm{a}$ & $0.34 \mathrm{a}$ & $0.61 \mathrm{~b}$ & $1.71 \mathrm{ab}$ & $0.27 \mathrm{~b}$ & $441.91 \mathrm{a}$ & $70.49 \mathrm{ab}$ & $28.16 \mathrm{~b}$ & $4.83 \mathrm{~b}$ \\
\hline Indian jujube $25 \%$ & $0.82 \mathrm{~b}$ & $0.32 \mathrm{a}$ & $0.52 \mathrm{c}$ & $1.51 \mathrm{~cd}$ & $0.25 \mathrm{bc}$ & $275.95 \mathrm{c}$ & $69.65 \mathrm{~b}$ & $27.33 \mathrm{bc}$ & $4.33 \mathrm{bc}$ \\
\hline Indian jujube $50 \%$ & $0.84 \mathrm{~b}$ & $0.34 \mathrm{a}$ & $0.77 \mathrm{a}$ & $1.83 \mathrm{a}$ & $0.31 \mathrm{a}$ & $226.11 \mathrm{c}$ & $61.98 \mathrm{c}$ & $36.49 \mathrm{a}$ & $7.17 \mathrm{a}$ \\
\hline
\end{tabular}

${ }^{\mathrm{z}}$ Means with the same letter are not significantly different (Fisher's least significant difference test at $5 \%$ level). 
Table 7. The $\mathrm{pH}$ and electrical conductivity (EC) of different substrates before inoculation and after harvesting.

\begin{tabular}{|c|c|c|c|c|}
\hline & \multicolumn{2}{|c|}{ Before inoculation } & \multicolumn{2}{|c|}{ After harvesting } \\
\hline & $\mathrm{pH}$ & $\overline{\mathrm{EC}(\mathrm{dS} / \mathrm{m})}$ & $\mathrm{pH}$ & $\overline{E C}(\mathrm{dS} / \mathrm{m})$ \\
\hline Sawdust 100\% & $6.25 \mathrm{a}^{\mathrm{z}}$ & $1.12 \mathrm{~d}$ & $4.91 \mathrm{~b}$ & $1.89 \mathrm{~d}$ \\
\hline Wax apple $25 \%$ & $6.06 \mathrm{a}$ & $1.64 \mathrm{c}$ & $4.96 \mathrm{~b}$ & $2.18 \mathrm{c}$ \\
\hline Wax apple $50 \%$ & $5.66 \mathrm{~b}$ & $2.07 \mathrm{~b}$ & $5.23 \mathrm{a}$ & $2.42 \mathrm{~b}$ \\
\hline Indian jujube $25 \%$ & $5.45 \mathrm{~b}$ & $2.11 \mathrm{~b}$ & $4.96 \mathrm{~b}$ & $2.15 \mathrm{c}$ \\
\hline Indian jujube $50 \%$ & $5.58 \mathrm{~b}$ & $2.61 \mathrm{a}$ & $5.31 \mathrm{a}$ & $2.92 \mathrm{a}$ \\
\hline
\end{tabular}

${ }^{\mathrm{z}}$ Means with the same letter are not significantly different (Fisher's least significant difference test at 5\% level).

mushroom cultivation, results that are consistent with Lee et al. (2009).

pH and EC values of substrates before inoculation and after harvesting. To determine the effect of substrate $\mathrm{pH}$ and $\mathrm{EC}$ values on king oyster mushroom growth, the $\mathrm{pH}$ and EC levels of different substrates were determined before inoculation. To determine how mycelium growth affects $\mathrm{pH}$ and $\mathrm{EC}$, the values were measured after harvesting. The initial $\mathrm{pH}$ values in Sawdust $100 \%$ and Wax apple $25 \%$ substrates before inoculation were 6.25 and 6.06 , respectively. These two $\mathrm{pH}$ values were significantly $(P<0.05)$ higher than those in the other substrates (Table 7). In contrast, the initial EC levels in Sawdust $100 \%$ and Wax apple $25 \%$ substrates before inoculation were 1.12 and $1.64 \mathrm{dS} / \mathrm{m}$, respectively, which were significantly $(P<$ $0.05)$ lower than those in other substrates (Table 7). Results from this study suggested that greater yield and growth occurred in substrate with a higher $\mathrm{pH}$ value (Tables 4 and 7). After harvesting, the $\mathrm{pH}$ was acidified, with all substrate showing $\mathrm{pH}$ values less than 5.31. The EC levels were greater after mycelium growth in all five substrates tested (Table 7). Consistent with our findings, Khan et al. (2013) suggested that $\mathrm{pH}$ plays a pivotal role in oyster mushroom production and that most mushrooms grow best with a near-neutral or slightly basic $\mathrm{pH}$.

\section{Conclusion}

In this study, the possibility of using sawdust mixed with ground fruit tree branches as substrate for cultivation of king oyster mushroom was evaluated. The results indicated that the best substitute for conventional sawdust was a substrate that contained $75 \%$ sawdust mixed with $25 \%$ ground wax apple branches. Furthermore, analyses revealed that mycelium and fruiting did not significantly change mineral content, slightly reduced $\mathrm{pH}$, and somewhat increased EC of the spent substrates. Overall, results from this study suggested that the pruning waste of fruit trees should be tested for potential utilization in king oyster mushroom production.

\section{Literature Cited}

Baysal, E. 2003. Cultivation of oyster mushroom on waste paper with some added supplementary materials. Bioresour. Technol. 89:95-97.

Council of Agriculture-Taiwan. 2013. Statistics Yearbook, p. 88-100. <http://agrstat.coa.gov. tw/sdweb/public/book/Book.aspx>.

Customs Administration, R.O.C. 2014. Ministry of Finance, Executive Yuan. Import Statistics of Wood Pallets during Jan.-Oct. 2014. The Inquiry System of Statistical Database. <https:// portal.sw.nat.gov.tw/APGA/GA03_LIST>.

Juang, L.D., C.C. Shiesh, and H.L. Lin. 2012. Effects of temperatures on the fruiting-body growth and development of king oyster mushroom (Pleurotus eryngii). Horticulture 37 (1):31-44

Khan, M.W., M.A. Ali, N.A. Khan, M.A. Khan, A. Rehman, and N. Javed. 2013. Effect of different levels of lime and $\mathrm{pH}$ on mycelial growth and production efficiency of oyster mushroom (Pleurotus spp.). Pak. J. Bot. 45:297-302.
Koshy, J. and P. Nambisan. 2012. Pretreatment of agricultural waste with Pleurotus $s p$. for ethanol production. Intl. J. Plant Anim. Environ. Sci. 2:244-249.

Kurt, S. and S. Buyukalaca. 2010. Yield performances and changes in enzyme activities of Pleurotus spp. (P. ostreatus and P. sajor-caju) cultivated on different agricultural wastes. Bioresour. Technol. 101:3164-3169.

Lee, C.Y., J.E. Park, B.B. Kim, S.M. Kim, and H.S. Ro. 2009. Determination of mineral components in the cultivation substrates of edible mushrooms and their uptake into fruiting bodies. Mycobiology 37:109-113.

Obodai, M., J. Cleland-Okine, and K.A. Vowotor 2003. Comparative study on the growth and yield of Pleurotus ostreatus mushroom on different lignocellulosic by-products. J. Ind. Microbiol. Biotechnol. 30:146-149.

Peng, J.T. 1997. Study on the effects of single and mixed sawdusts of different origins on the production of Pleurotus eryngii. J. Agr. Res. China 46:51-59.

Petre, M. and A. Teodorescu. 2012. Biotechnology of agricultural wastes recycling through controlled cultivation of mushrooms. In: M. Petre (ed). Advances in applied biotechnology. InTech. ISBN: 978-953-307-820-5.

Poppe, J. 2000. Use of agricultural waste materials in the cultivation of mushrooms. Mushroom Sci 15:3-23.

Rani, P., N. Kalyani, and K. Prathiba. 2008. Evaluation of lignocellulosic wastes for production of edible mushrooms. Appl. Biochem. Biotechnol. 151:151-159.

Sharma, R.K. and D.S. Arora. 2015. Fungal degradation of lignocellulosic residues: An aspect of improved nutritive quality. Crit. Rev. Microbiol. 41:52-60.

Sherief, A., A. El-Tanash, and A. Temraz. 2010 Lignocellulolytic enzymes and substrate utilization during growth and fruiting of Pleurotus ostreatus on some solid wastes. J. Environ. Sci. Technol 3:18-34.

Yamanaka, K. 2011. Mushroom cultivation in Japan. WSMBMP Bul. 4:1-10.

Yildiz, S., U.C. Yildiz, E.D. Gezer, and A. Temiz. 2002. Some lignocellulosic wastes used as raw material in cultivation of the Pleurotus ostreatus culture mushroom. Process Biochem. 38:301-306.

Zervakis, G.I. 2005. Cultivation of the king-oyster mushroom Pleurotus eryngii on substrates deriving from the olive-oil industry. Intl. J. Med. Mushrooms 7:486-487. 